\title{
Predictive Significance of C-reactive Protein-to-albumin Ratio for Postoperative Pancreatic Fistula After Pancreaticoduodenectomy
}

\author{
TERUHISA SAKAMOTO, YAKUKI YAGYU, EI UCHINAKA, MASAKI MORIMOTO, \\ TAKEHIKO HANAKI, NARUO TOKUYASU, SOICHIRO HONJO and YOSHIYUKI FUJIWARA \\ Division of Surgical Oncology, Department of Surgery, School of Medicine, \\ Tottori University Faculty of Medicine, Yonago, Japan
}

\begin{abstract}
Background/Aim: The usefulness of C-reactive protein-to-albumin ratio $(C A R)$ as a predictive indicator for clinically-relevant postoperative pancreatic fistula $(C R$ $P O P F)$ after pancreaticoduodenectomy (PD) is unclear. We performed a retrospective analysis to identify reliable inflammatory indicators for prediction of CR-POPF after PD. Patients and Methods: We enrolled 160 consecutive patients who underwent $P D$. Multivariate logistic regression analysis was performed. The areas under curves (AUCs) were compared with the discriminatory ability of inflammatory indicators, namely, $C$-reactive protein $(C R P)$, neutrophil-to-lymphocyte ratio (NLR), platelet-to-lymphocyte ratio $(P L R)$, platelet count multiplied by $C$-reactive protein (P-CRP), and CAR. Results: The AUC for CAR on POD 3 to predict $C R-P O P F$ was $0.782(p<0.001)$ and higher than that for CRP (0.773), NLR (0.652), PLR (0.504), and P-CRP (0.703). Multivariate analysis revealed that CAR on POD 3 was an independent predictive indicator of CR-POPF. Conclusion: $C A R$ on POD 3 is a reliable predictor of $C R$ $P O P F$ after $P D$.
\end{abstract}

Pancreaticoduodenectomy (PD) is a complex procedure associated with high morbidity and mortality and performed in patients with malignant or benign tumors of the pancreatic head and periampullary region. Despite recent dramatic advances in surgical techniques and developments in perioperative management, reported morbidity and mortality

Correspondence to: Teruhisa Sakamoto, Division of Surgical Oncology, Department of Surgery, School of Medicine, Tottori University Faculty of Medicine, 36-1 Nishi-cho, Yonago 683-8504, Japan. Tel: +81 859386567, Fax: +81 859386569, e-mail: tesakamo@tottori-u.ac.jp

Key Words: C-reactive protein-to-albumin ratio, postoperative pancreatic fistula. rates after PD are $41.56 \%$ and $2.88 \%$, respectively, according to the national clinical database in Japan and other sources, and these rates are unsatisfactory (1-6). Postoperative pancreatic fistula (POPF) is the most frequent and clinicallycrucial complication following PD. Clinically-relevant POPF (CR-POPF) sometimes triggers life-threatening complications such as postoperative intra-abdominal hemorrhage, intra-abdominal abscess, sepsis, and death (7-9). Therefore, accurate and rapid prediction of CR-POPF after PD is needed to decrease mortality secondary to serious complications and to optimize individual patient's treatment decisions.

The amylase level in pancreatic drainage fluid is a reliable predictive indicator for CR-POPF after PD $(10,11)$. However, it is sometimes difficult to predict CR-POPF by the measurement of drainage fluid amylase levels accurately because the concentration of amylase does not always reflect the severity of POPF (12). Systemic inflammatory responses are closely associated with surgical complications in various types of surgery (13-16). C-reactive protein (CRP), an inflammatory marker, is a well-recognized positive acutephase nonspecific reactant synthesized by the liver that increases rapidly in response to inflammation and infection. CRP has been assessed as a predictive indicator of POPF (17-19). C-reactive protein-to-albumin ratio (CAR) is another inflammatory indicator calculated by dividing serum CRP by albumin levels, and has been correlated with poor prognosis in cancer patients and patients with sepsis $(20,21)$. Moreover, CAR is a useful biomarker for monitoring activity in systemic inflammatory disease (22); however, the usefulness of CAR as a predictive indicator of CR-POPF after PD remains unclear. Therefore, this study aimed to investigate the predictive significance of CAR for CR-POPF after PD compared with both CRP and other serum-based inflammatory indicators, namely, neutrophil-to-lymphocyte ratio (NLR), platelet-to-lymphocyte ratio (PLR), and platelet multiplied by CRP (P-CRP). 
Table I. Patient clinical characteristics.

\begin{tabular}{|c|c|c|c|}
\hline Variable & CR-POPF $(n=48)$ & nonCR-POPF $(\mathrm{n}=112)$ & $p$-Value \\
\hline Age (years) & $69.1 \pm 10.6$ & $68.9 \pm 12.3$ & 0.839 \\
\hline Gender (male:female) & $36: 12$ & $61: 51$ & 0.015 \\
\hline Body mass index & $23.2 \pm 3.2$ & $21.8 \pm 3.0$ & 0.011 \\
\hline Histological diagnosis & & & 0.007 \\
\hline Pancreatic ductal adenocarcinoma & $9(18.8 \%)$ & $53(47.3 \%)$ & \\
\hline Acinar cell cancer & $18(37.5 \%)$ & $15(13.4 \%)$ & \\
\hline Bile duct cancer & $0(0 \%)$ & $1(0.9 \%)$ & \\
\hline Carcinoma of the papilla of Vater & $11(22.9 \%)$ & $17(15.2 \%)$ & \\
\hline IPMN & $5(10.4 \%)$ & $12(10.7 \%)$ & \\
\hline PNET & $1(2.1 \%)$ & $6(5.4 \%)$ & \\
\hline SPN & $1(2.1 \%)$ & $1(0.9 \%)$ & \\
\hline Others & $3(6.3 \%)$ & $7(6.3 \%)$ & \\
\hline Preoperative serum albumin $(\mathrm{g} / \mathrm{dl})$ & $3.9 \pm 0.7$ & $3.9 \pm 0.6$ & 0.827 \\
\hline Preoperative peripheral lymphocyte count $(/ \mu \mathrm{l})$ & $1604 \pm 520$ & $1518 \pm 522$ & 0.365 \\
\hline Preoperative biliary drainage (present:absent) & $26: 22$ & $45: 67$ & 0.103 \\
\hline Pancreatic parenchymal texture (soft:hard) & $43: 5$ & $53: 59$ & $<0.001$ \\
\hline Diameter of the main pancreatic duct (mm) & $3.4 \pm 1.8$ & $4.7 \pm 2.5$ & $<0.001$ \\
\hline Operative time $(\mathrm{min})$ & $551 \pm 101$ & $524 \pm 103$ & 0.231 \\
\hline Blood loss volume $(\mathrm{ml})$ & $806 \pm 710$ & $677 \pm 517$ & 0.328 \\
\hline Type of PJ (modified BA:modified Kakita) & $22: 26$ & $71: 41$ & 0.039 \\
\hline
\end{tabular}

CR-POPF: Clinically-relevant postoperative pancreatic fistula; IPMN: intraductal papillary mucinous neoplasm; PNET: pancreatic neuroendocrine tumor; SPN: solid pseudopapillary neoplasm; PJ: pancreaticojejunostomy; BA: Blumgart anastomosis. Continuous variables are expressed as mean \pm standard deviation.

\section{Patients and Methods}

Patients. In this study, we retrospectively reviewed data from 160 consecutive patients who underwent PD for pancreatic head and periampullary disease at Tottori University Hospital between January 2008 and December 2017

The study protocol was approved by the institutional review board of Tottori University (No. 17A135), and the requirement for informed consent was waived for this retrospective study.

Surgical procedures. All patients underwent subtotal stomachpreserving PD or pylorus-preserving PD. Reconstruction was performed by modified Child's reconstruction in subtotal stomachpreserving PD or a Traverso reconstruction in pylorus-preserving PD. Pancreases with soft parenchyma were divided using a scalpel or an ultrasonically-activated device, while hard pancreatic parenchyma was divided using an electric scalpel.

Pancreaticojejunostomy (PJ) was performed by a duct to mucosal, end-to-side anastomosis method using eight interrupted 50 polydioxanone sutures (PDS-II; Johnson and Johnson Co., Tokyo, Japan) with either an internal or external stent in the main pancreatic duct for drainage of pancreatic juice. In a seromuscularparenchymal anastomosis, either Kakita's method or the modified Blumgart method was performed using 3-0 or 4-0 nonabsorbable sutures $(23,24)$. Hepaticojejunostomy was performed $10-15 \mathrm{~cm}$ distal to the PJ, followed by antecolic end-to-side gastro- or duodenojejunostomy with a Braun anastomosis. At the end of the operation, closed peritoneal drainage tubes were placed at the upper and lower side of the PJ and behind the hepaticojejunostomy after peritoneal lavage was performed using $8000 \mathrm{ml}$ of normal saline.
Perioperative management. Prophylactic antibiotics were administered for 3 days, including the operation day, in all patients. Proton pump inhibitors were provided to patients throughout the postoperative course. Solid diets were started on postoperative day (POD) 4 regardless of amylase levels in the drainage fluid, if there were no serious postoperative surgical complications.

Amylase levels in the drainage fluid were routinely measured on POD 1 and 3. Similarly, bacterial culture and bacterial smear test of the drainage fluid were performed on POD 1 and 3 . We removed peritoneal drainage tubes on POD 3 or 4 , when the amylase levels in the drainage fluid were less than three times the upper limit of our institutional normal serum value or less than $1000 \mathrm{IU} / 1$ as an absolute value and bacterial smear test of the drainage fluid was confirmed negative on POD 3 . We routinely used antibiotics and replaced the drains to prevent drainage failure secondary to occlusion of the drainage tract in patients with the possibility of developing CR-POPF; we removed the drains after complete PF recovery. Nasogastric tubes inserted intraoperatively were removed from all patients on POD 1.

POPF was diagnosed in accordance with the International Study Group Pancreatic Fistula classification (25). In the current study, we regarded grade $\mathrm{B}$ or $\mathrm{C}$ as $\mathrm{CR}-\mathrm{POPF}$ and divided the patients into a CR-POPF group and a nonCR-POPF group.

Clinical variables. We retrospectively reviewed the following clinical variables evaluated in this study using patients' electronic medical records: age, sex, body mass index, histological diagnosis, preoperative serum albumin level, preoperative peripheral lymphocyte count, preoperative biliary drainage, texture of the pancreatic parenchyma, diameter of the main pancreatic duct (MPD), operation time, intraoperative blood loss volume, and type 
Table II. Patients' postoperative drain amylase concentrations and serum inflammatory parameters.

\begin{tabular}{lccc}
\hline Variable & CR-POPF $(\mathrm{n}=48)$ & NonCR-POPF $(\mathrm{n}=112)$ & $p$-Value \\
\hline Amylase level in the drainage fluid on POD 1 (IU/l) $(\mathrm{n}=160)$ & $45453 \pm 146635$ & $5457 \pm 11684$ & $<0.001$ \\
Amylase level in the drainage fluid on POD 3 (IU/l) $(\mathrm{n}=156)^{\mathrm{a}}$ & $3275 \pm 7171$ & $656 \pm 2435$ & $<.8 \pm 2.5$ \\
CRP on POD 1 (mg/dl) $(\mathrm{n}=160)$ & $8.7 \pm 3.2$ & $13.9 \pm 10.3$ & 0.139 \\
NLR on POD 1 $(\mathrm{n}=153)^{\mathrm{b}}$ & $13.4 \pm 7.2$ & $269.0 \pm 183.9$ & 0.941 \\
PLR on POD 1 $(\mathrm{n}=153)^{\mathrm{c}}$ & $247.1 \pm 101.9$ & $136.4 \pm 72.9$ & 0.936 \\
P-CRP on POD 1 $(\mathrm{n}=160)$ & $154.5 \pm 78.4$ & $3.0 \pm 1.1$ & 0.197 \\
CAR on POD 1 $(\mathrm{n}=159)^{\mathrm{d}}$ & $3.3 \pm 1.3$ & $12.1 \pm 5.9$ & 0.231 \\
CRP on POD 3 $(\mathrm{mg} / \mathrm{dl})(\mathrm{n}=157)^{\mathrm{e}}$ & $20.1 \pm 8.2$ & $8.5 \pm 4.2$ & $<0.001$ \\
NLR on POD 3 $(\mathrm{n}=155)^{\mathrm{f}}$ & $10.1 \pm 3.6$ & $202.2 \pm 97.6$ & 0.003 \\
PLR on POD 3 $(\mathrm{n}=155)^{\mathrm{g}}$ & $195.1 \pm 78.1$ & $212.0 \pm 158.1$ & 0.959 \\
P-CRP on POD 3 $(\mathrm{n}=157)^{\mathrm{h}}$ & $339.5 \pm 207.2$ & $4.6 \pm 2.3$ & $<0.001$ \\
CAR on POD 3 $(\mathrm{n}=156)^{\mathrm{i}}$ & $8.0 \pm 3.3$ & $<0.001$ \\
\hline
\end{tabular}

CR-POPF: Clinically relevant postoperative pancreatic fistula; POD: postoperative day; CRP: C-reactive protein; NLR: neutrophil-to-lymphocyte ratio; PLR: platelet-to-lymphocyte ratio; P-CRP: platelet multiplied by C-reactive protein/104; CAR: C-reactive protein-to-albumin ratio. Continuous variables are expressed as mean \pm standard deviation. ${ }^{a}, \mathrm{i}$ data not available for four patients; ${ }^{b, c}$ data not available for seven patients; ${ }^{\mathrm{d}} \mathrm{data}$ not available for one patient; ${ }^{e, h}$ data not available for three patients; $f, g$ data not available for five patients.

of PJ. We also collected data for CRP, NLR, PLR, P-CRP, and CAR on POD 1 and 3 as postoperative inflammatory indicators, from peripheral blood samples.

We calculated CAR by dividing serum CRP level by the peripheral serum albumin level. We calculated NLR and PLR by dividing the peripheral neutrophil count and the peripheral platelet count by the peripheral lymphocyte count, respectively. P-CRP was calculated by multiplying the peripheral platelet count by serum CRP level/104.

Statistical analysis. Continuous variables were expressed as means and deviations. Differences in clinical variables between the two groups were examined by the Chi-square test, Fisher's exact probability test, and the Mann-Whitney $U$-test. The areas under the curves (AUC) for the amylase level in the drainage fluid, CRP, NLR, PLR, P-CRP, and CAR regarding each measurement's ability to predict CR-POPF were evaluated using receiver operating characteristic (ROC) analysis. The optimal cutoff values for CAR and the amylase level in the drainage fluid were also calculated by ROC analysis. Univariate and multivariate logistic regression analyses were performed to clarify the predictive factors of CRPOPF after PD. Covariates with a $p$-value $<0.1$ in the univariate analysis were entered into the multivariate analysis. $p<0.05$ was considered significant. All statistical analyses were performed using SPSS software (Version 24; SPSS Inc., Chicago, IL, USA).

\section{Results}

CR-POPF occurred in 48/160 (30.8\%) patients. Patients' characteristics in both the CR-POPF group and nonCRPOPF group are shown in Table I. There were significant differences between the two groups regarding sex, historical diagnosis, texture of the pancreatic parenchyma, and type of PJ. The body mass index of patients in the CR-POPF group was significantly higher compared with patients in the
nonCR-POPF group. The diameter of the MPD in patients in the CR-POPF group was significantly shorter than that of patients in the nonCR-POPF group. We observed no significant differences in preoperative serum albumin level and peripheral lymphocyte count, reflecting preoperative nutritional status, between the two groups.

Table II summarizes the postoperative findings of the drain amylase concentrations and serum inflammatory parameters in the patients in the current study. Amylase levels in the drainage fluid on both POD 1 and 3, and CRP, NLR, P-CRP, and CAR on POD 3 in patients in the CRPOPF group were significantly higher than those in patients in the nonCR-POPF group. ROC analysis regarding the prediction of CR-POPF revealed that the AUCs for serum CRP level and amylase level in the drainage fluid on POD 3 were $0.773(p<0.001)$ and $0.835(p<0.001)$, respectively. In contrast, AUCs for values on POD 1 were $0.558(p=0.259)$ and $0.831(p<0.001)$, respectively, which were lower than those on POD 3 (Figure 1).

The discrimination ability of CAR to predict CP-POPF, estimated by AUC, was $0.782(p<0.001)$, which was the highest value among all inflammatory indicators on POD 3 (CRP: 0.773, $p<0.001$; NLR: 0.652, $p=0.003$; PLR: 0.504, $p=0.943$; and P-CRP: 0.703, $p<0.001$ ) (Figures 1 and 2). In the ROC analysis, the highest Youden indices (sensitivity + specificity - 1) showed the optimal cutoff value of CAR on POD 3 to be 7.4. Based on this result, we grouped patients as CARHigh (CAR $\geq 7.4 ; n=43$ ) or CARLow (CAR $<7.4$; $\mathrm{n}=113$ ). Table III shows the relationship between CAR and the clinical characteristics of patients who underwent PD. Significant differences were observed between CAR and sex $(p=0.026)$, pancreatic parenchymal texture $(p<0.001)$, MPD 


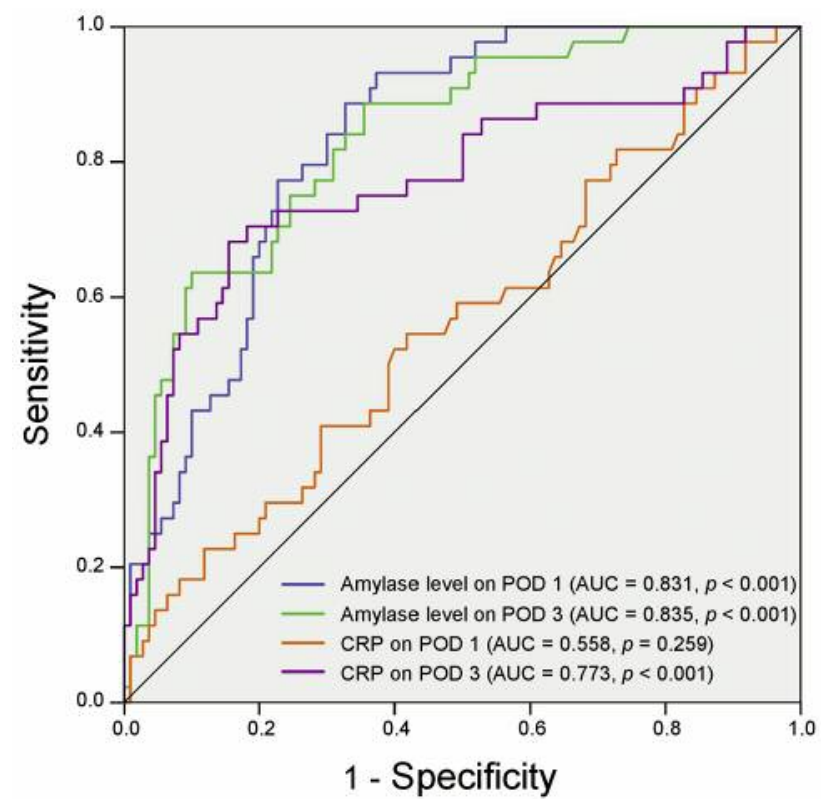

Figure 1. Receiver operating characteristic curves for serum CRP levels and amylase levels in drainage fluid on POD 1 and 3 to predict clinically-relevant postoperative pancreatic fistula in patients who underwent pancreaticoduodenectomy. CRP: C-reactive protein; AUC: area under the curve; POD: postoperative day.

diameter $(p<0.001)$, amylase level in the drainage fluid on POD $3(p<0.001)$, and CR-POPF $(p<0.001)$.

Multivariate logical regression analyses revealed that CAR on POD 3 was an independent predictive factor of CR-POPF after PD, along with amylase level in the drainage fluid on POD 3 (Table IV).

\section{Discussion}

Our results showed that CAR was the most reliable indicator for predicting CR-POPF following PD among the inflammatory indicators evaluated. CR-POPF is a serious complication and causes potentially life-threatening complications that can lead to sepsis secondary to intraabdominal abscess, or postpancreatectomy hemorrhage (26, 27). CR-POPF leads to prolonged hospital stay and increased medical costs. Furthermore, CR-POPF causes a poor prognosis in patients with malignant disease secondary to depleted systemic immune function or delayed administration of adjuvant therapy $(28,29)$. Because no definitive methods exist to completely prevent CR-POPF, despite several studies, accurate and reliable prediction of CR-POPF in the early postoperative period after PD is needed to prevent these complications.

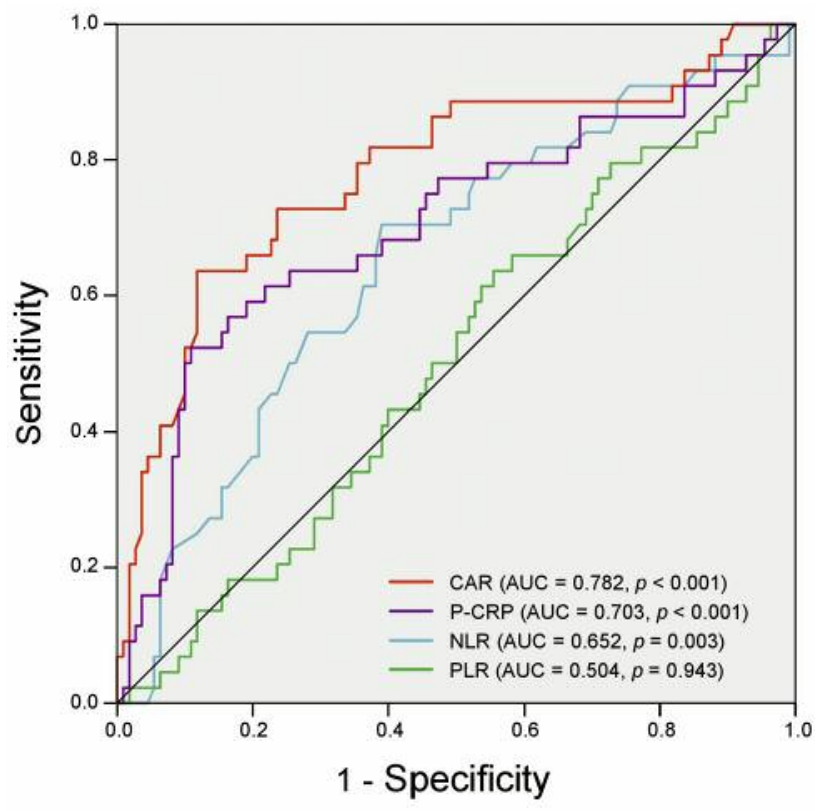

Figure 2. Receiver operating characteristic curves for CAR, P-CRP, $N L R$, and PLR on POD 3 to predict clinically postoperative pancreatic fistula in patients who underwent pancreaticoduodenectomy. CAR: $C$ reactive protein-to-albumin ratio; P-CRP: platelet multiplied by CRP; NLR: neutrophil-to-lymphocyte ratio; PLR: platelet-to-lymphocyte ratio; POD: postoperative day; AUC: area under the curve.

Drain amylase concentration is the most well-known predictive indicator for CR-POPF (11). Several reports have indicated that high amylase levels in the drainage fluid, perioperatively, are an independent predictive risk factor for CR-POPF $(10,30)$. Our results confirmed that the amylase level in the drainage fluid was an independent predictive indicator for CR-POPF after PD. However, in contrast, one study reported that the amylase level in the drainage fluid does not always reflect the clinical severity of POPF (12). This may be because amylase consists of glycolytic enzymes and does not damage tissues directly as with pancreatic peptidases; one study reported a nonparallel correlation in secretion between amylase and pancreatic peptidases (31). As another reason, measuring the amylase level has the shortcoming of being susceptible to the location or condition of the inserted peritoneal drainage tube, and evaluating CRPOPF might not be performed correctly due to drain migration and obstruction. Therefore, it is desirable to predict CR-POPF using objective surrogate markers unaffected by the surgical procedure.

CRP is a positive acute-phase reactant synthesized by the liver and a hallmark of systemic inflammation that is widely used as a blood marker in medical treatment (17). Serum CRP levels generally increase acutely in response to 
Table III. Comparison of the clinical variables in the CAR High group and CAR ${ }^{\text {Low }}$ group in patients who underwent PD.

\begin{tabular}{|c|c|c|c|}
\hline Variables & $\mathrm{CAR}^{\text {High }}(\geq 7.4 ; \mathrm{n}=43)$ & $\operatorname{CAR}^{\text {Low }}(<7.4 ; \mathrm{n}=113)$ & $p$-Value \\
\hline Age (years) & $69.6 \pm 9.3$ & $68.9 \pm 12.2$ & 0.861 \\
\hline Gender (male:female) & $32: 11$ & $62: 51$ & 0.026 \\
\hline Body mass index & $22.9 \pm 3.0$ & $21.9 \pm 3.1$ & 0.052 \\
\hline Preoperative serum albumin $(\mathrm{g} / \mathrm{dl})$ & $3.9 \pm 0.7$ & $3.9 \pm 06$ & 0.979 \\
\hline Preoperative peripheral lymphocyte count $(/ \mu \mathrm{l})$ & $1657 \pm 554$ & $1496 \pm 509$ & 0.118 \\
\hline Preoperative biliary drainage (present:absent) & $19: 24$ & $51: 62$ & 0.915 \\
\hline Pancreatic parenchymal texture (soft:hard) & $37: 6$ & $56: 57$ & $<0.001$ \\
\hline Diameter of the main pancreatic duct (mm) & $3.4 \pm 1.8$ & $4.8 \pm 2.4$ & $<0.001$ \\
\hline Operative time $(\mathrm{min})$ & $547 \pm 93$ & $527 \pm 106$ & 0.286 \\
\hline Blood loss volume $(\mathrm{ml})$ & $730 \pm 543$ & $685 \pm 518$ & 0.648 \\
\hline Type of PJ (modified BA:modified Kakita) & $25: 18$ & $67: 46$ & 0.896 \\
\hline Amylase level in the drainage fluid on POD 3 (IU/l) & $2570 \pm 6590$ & $1019 \pm 3509$ & $<0.001$ \\
\hline CR-POPF (present:absent) & $30: 13$ & 16:97 & $<0.001$ \\
\hline
\end{tabular}

PD: Pancreaticoduodenectomy; CAR: C-reactive protein-to-albumin ratio; PJ: pancreaticojejunostomy; BA: Blumgart anastomosis; POD: postoperative day; CR-POPF: clinically-relevant postoperative pancreatic fistula. Continuous variables are expressed as mean \pm standard deviation.

Table IV. Univariate and multivariate analyses of predictive indicators for CR-POPF in patients undergoing PD.

\begin{tabular}{|c|c|c|c|c|c|c|}
\hline \multirow[b]{2}{*}{ Variables } & \multicolumn{3}{|c|}{ Univariate analysis } & \multicolumn{3}{|c|}{ Multivariate analysis } \\
\hline & Odds ratio & $95 \% \mathrm{CI}$ & $p$-Value & Odds ratio & $95 \% \mathrm{CI}$ & $p$-Value \\
\hline Age $(\geq 70$ years $v s .<70$ years $)$ & 0.730 & $0.370-1.442$ & 0.365 & & & \\
\hline Sex (male $v s$. female) & 2.508 & $1.183-5.319$ & 0.017 & 1.811 & $0.684-4.796$ & 0.232 \\
\hline Body mass index $(\geq 25 v s .<25)$ & 2.600 & $1.114-6.070$ & 0.027 & 2.141 & $0.588-7.793$ & 0.248 \\
\hline Operative time ( $\geq 480 \mathrm{~min} v s .<480 \mathrm{~min})$ & 1.496 & $0.710-3.150$ & 0.289 & & & \\
\hline Blood loss volume $(\geq 1000 \mathrm{ml} v s .<1000 \mathrm{ml})$ & 1.444 & $0.644-3.239$ & 0.372 & & & \\
\hline Pancreatic parenchymal texture (soft $v s$. hard) & 9.574 & $3.530-25.961$ & $<0.001$ & 2.762 & $0.722-10.566$ & 0.138 \\
\hline Diameter of the main pancreatic duct $(\geq 3 \mathrm{~mm} v s .<3 \mathrm{~mm})$ & 3.816 & $1.878-7.754$ & $<0.001$ & 1.549 & $0.568-4.223$ & 0.393 \\
\hline Preoperative biliary drainage (present $v s$. absent) & 1.760 & $0.890-3.480$ & 0.104 & & & \\
\hline Type of PJ (modified BA vs. Kakita) & 0.489 & $0.246-0.970$ & 0.041 & 0.419 & $0.163-1.072$ & 0.070 \\
\hline Amylase level in the drainage fluid on POD 3 ( $\geq 867.5 \mathrm{IU} / 1$ ss. $<867.5 \mathrm{IU} / \mathrm{l})$ & 15.353 & $6.471-36.426$ & $<0.001$ & 3.938 & $1.304-11.893$ & 0.015 \\
\hline CAR on POD $3(\geq 7.4 v s .<7.4 \mathrm{IU} / 1)$ & 13.990 & $6.048-32.361$ & $<0.001$ & 8.055 & $3.048-21.288$ & $<0.001$ \\
\hline
\end{tabular}

PD: Pancreaticoduodenectomy; CI: confidence interval; PJ: pancreaticojejunostomy; BA: Blumgart anastomosis; CAR: C-reactive protein-to-albumin ratio; POD: postoperative day.

inflammation and infection and peak at approximately 48-72 h (32). Several reports have shown that serum CRP level on POD 3 is a useful indicator for predicting CR-POPF after PD $(18,33)$. Our results confirmed that serum CRP levels on POD 3 in patients with CR-POPF were significantly higher than levels in patients with nonCR-POPF, which supports the close relationship between CRP on POD 3 and CR-POPF. However, individual differences in the distributions of serum CRP levels have been noted, related to genetic or environmental factors (34). Moreover, there is a significant association between regulation of serum CRP levels and polymorphisms in the promoter of interleukin-6 (34). Because of these individual differences, CRP alone might not accurately predict CR-POPF.
CAR, calculated by dividing the serum CRP level by the serum albumin level, is a new inflammatory indicator that is widely used as a prognostic indictor in various cancers as well as in inflammatory disease $(35,36)$. Albumin is a negative acute-phase reactant, and its level in the blood decreases in response to the degree of inflammation during catabolism, and hypoalbuminemia is associated with inflammation severity, disease prognosis, and mortality (37, 38). Therefore, CAR reflects acute inflammatory intensity, incorporating individual differences, by dividing CRP by albumin. In fact, CAR was reportedly superior to CRP level in predicting mortality in patients with septic shock (21). In the current study, we demonstrated that the AUC of CAR on POD 3 was the best predictor of CR-POPF among the 
inflammatory indicators, including CRP on POD 3, and that CAR was an independent predictive indicator of CR-POPF.

Platelets are implicated in many pathophysiological processes including inflammation and immunity (39). However, different from acute inflammatory reactants such as CRP or albumin, platelet numbers begin to increase after peak inflammation (40). Platelets are consumed during hemostasis secondary to intraoperative bleeding or platelet aggregation in the acute inflammatory phase in highlyinvasive surgeries such as PD. Therefore, inflammatory indicators based on the platelet count, such as PLR and PCRP, are unsuitable to predict CR-POPF following PD early postoperatively, before peak inflammation.

The present study has limitations, including that this was a retrospective analysis with a limited number of enrolled patients, which generated bias. Additionally, although we measured CAR on POD 1 and 3, only, the optimal time to measure CAR remained unclear. Other inflammatory indicators, such as the albumin-to-fibrinogen ratio, red cell distribution width and, the mean platelet volume, in addition to the five inflammatory indicators verified in this study, should be estimated to identify the true reliable predictive indicators for CR-POPF after PD.

In conclusion, based on our result, CAR on POD 3 was a reliable predictive indicator of CR-POPF after PD. Furthermore, accurately and quickly predicting CR-POPF after PD using CAR may prevent life-threatening complications and provide optimal individual patient treatment.

\section{Conflicts of Interest}

The Authors have no conflicts of interests to declare regarding this study.

\section{Authors' Contributions}

Study concepts: Teruhisa Sakamoto; Study design: Teruhisa Sakamoto; Data acquisition: Takuki Yagyu, Ei Uchinaka, Masaki Morimoto, and Takehiko Hanaki; Quality control of data and algorithms: Joji Watanabe; Data analysis and interpretation; Teruhisa Sakamoto and Naruo Tokuyasu; Statistical analysis: Teruhisa Sakamoto; Manuscript preparation: Teruhisa Sakamoto; Manuscript editing: Soichiro Honjo; Manuscript review: Yoshiyuki Fujiwara; Final approval of the article, all Authors.

\section{Acknowledgements}

The Authors would like to thank Jane Charbonneau, DVM, from Edanz Group (www.edanzediting.com/ac) for editing a draft of this manuscript.

\section{References}

1 Aoki S, Miyata H, Konno H, Gotoh M, Motoi F, Kumamaru H, Wakabayashi G, Kakeji Y, Mori M, Seto Y and Unno M: Risk factors of serious postoperative complications after pancreaticoduodenectomy and risk calculators for predicting postoperative complications: A nationwide study of 17,564 patients in japan. J Hepatobiliary Pancreat Sci 24(5): 243-251, 2017. PMID: 28196308. DOI: $10.1002 /$ jhbp. 438

2 Ceppa EP, Pitt HA, Nakeeb A, Schmidt CM, Zyromski NJ, House MG, Kilbane EM, George-Minkner AN, Brand B and Lillemoe KD: Reducing readmissions after pancreatectomy: Limiting complications and coordinating the care continuum. J Am Coll Surg 221(3): 708-716, 2015. PMID: 26228016. DOI: 10.1016/j.jamcollsurg.2015.05.012

3 McPhee JT, Hill JS, Whalen GF, Zayaruzny M, Litwin DE, Sullivan ME, Anderson FA and Tseng JF: Perioperative mortality for pancreatectomy: A national perspective. Ann Surg 246(2): 246-253, 2007. PMID: 17667503. DOI: 10.1097/01.sla.00 $00259993.17350 .3 \mathrm{a}$

4 Mogal H, Vermilion SA, Dodson R, Hsu FC, Howerton R, Shen $\mathrm{P}$ and Clark CJ: Modified frailty index predicts morbidity and mortality after pancreaticoduodenectomy. Ann Surg Oncol 24(6): 1714-1721, 2017. PMID: 28058551. DOI: 10.1245/s10434-0165715-0

5 Vollmer CM, Jr., Sanchez N, Gondek S, McAuliffe J, Kent TS, Christein JD and Callery MP: A root-cause analysis of mortality following major pancreatectomy. J Gastrointest Surg 16(1): 89102; discussion 102-103, 2012. PMID: 22065319. DOI: 10.1007/s11605-011-1753-x

6 Cameron JL and $\mathrm{He}$ J: Two thousand consecutive pancreaticoduodenectomies. J Am Coll Surg 220(4): 530-536, 2015. PMID: 25724606. DOI: 10.1016/j.jamcollsurg.2014.12.031

7 Choi SH, Moon HJ, Heo JS, Joh JW and Kim YI: Delayed hemorrhage after pancreaticoduodenectomy. J Am Coll Surg 199(2): 186-191, 2004. PMID: 15275871. DOI: 10.1016/ j.jamcollsurg.2004.04.005

8 DeOliveira ML, Winter JM, Schafer M, Cunningham SC, Cameron JL, Yeo CJ and Clavien PA: Assessment of complications after pancreatic surgery: A novel grading system applied to 633 patients undergoing pancreaticoduodenectomy. Ann Surg 244(6): 931-937; discussion 937-939, 2006. PMID: 17122618. DOI: $10.1097 / 01$ sla.0000246856.03918.9a

9 Kawai M, Tani M, Terasawa H, Ina S, Hirono S, Nishioka R, Miyazawa M, Uchiyama K and Yamaue H: Early removal of prophylactic drains reduces the risk of intra-abdominal infections in patients with pancreatic head resection: Prospective study for 104 consecutive patients. Ann Surg 244(1): 1-7, 2006. PMID: 16794381. DOI: 10.1097/01.sla.0000218077.14035.a6

10 Kawai M, Kondo S, Yamaue H, Wada K, Sano K, Motoi F, Unno M, Satoi S, Kwon AH, Hatori T, Yamamoto M, Matsumoto J, Murakami Y, Doi R, Ito M, Miyakawa S, Shinchi H, Natsugoe $\mathrm{S}$, Nakagawara H, Ohta T and Takada T: Predictive risk factors for clinically relevant pancreatic fistula analyzed in 1,239 patients with pancreaticoduodenectomy: Multicenter data collection as a project study of pancreatic surgery by the japanese society of hepato-biliary-pancreatic surgery. J Hepatobiliary Pancreat Sci 18(4): 601-608, 2011. PMID: 21491103. DOI: $10.1007 / \mathrm{s} 00534-011-0373-x$

11 Bassi C, Dervenis C, Butturini G, Fingerhut A, Yeo C, Izbicki J, Neoptolemos J, Sarr M, Traverso W and Buchler M: Postoperative pancreatic fistula: An international study group (isgpf) definition. Surgery 138(1): 8-13, 2005. PMID: 16003309. DOI: $10.1016 /$ j.surg.2005.05.001 
12 Gebauer F, Kloth K, Tachezy M, Vashist YK, Cataldegirmen G, Izbicki JR and Bockhorn M: Options and limitations in applying the fistula classification by the international study group for pancreatic fistula. Ann Surg 256(1): 130-138, 2012. PMID: 22504279. DOI: 10.1097/SLA.0b013e31824f24e4

13 Rettig TC, Verwijmeren L, Dijkstra IM, Boerma D, van de Garde EM and Noordzij PG: Postoperative interleukin-6 level and early detection of complications after elective major abdominal surgery. Ann Surg 263(6): 1207-1212, 2016. PMID: 26135695. DOI: $10.1097 /$ SLA.0000000000001342

14 Sinning JM, Scheer AC, Adenauer V, Ghanem A, Hammerstingl C, Schueler R, Muller C, Vasa-Nicotera M, Grube E, Nickenig $\mathrm{G}$ and Werner N: Systemic inflammatory response syndrome predicts increased mortality in patients after transcatheter aortic valve implantation. Eur Heart J 33(12): 1459-1468, 2012. PMID: 22285582. DOI: $10.1093 /$ eurheartj/ehs002

15 Amar D, Zhang H, Park B, Heerdt PM, Fleisher M and Thaler HT: Inflammation and outcome after general thoracic surgery. Eur J Cardiothorac Surg 32(3): 431-434, 2007. PMID: 17643996. DOI: 10.1016/j.ejcts.2007.06.017

16 van Hilst J, Brinkman DJ, de Rooij T, van Dieren S, Gerhards MF, de Hingh IH, Luyer MD, Marsman HA, Karsten TM, Busch OR, Festen S, Heger M and Besselink MG: The inflammatory response after laparoscopic and open pancreatoduodenectomy and the association with complications in a multicenter randomized controlled trial. HPB (Oxford), 2019. PMID: 30975599. DOI: 10.1016/j.hpb.2019.03.353

17 Pepys MB and Hirschfield GM: C-reactive protein: A critical update. J Clin Invest 111(12): 1805-1812, 2003. PMID: 12813013. DOI: $10.1172 / \mathrm{JCI} 18921$

18 Hiyoshi M, Chijiiwa K, Fujii Y, Imamura N, Nagano M and Ohuchida J: Usefulness of drain amylase, serum c-reactive protein levels and body temperature to predict postoperative pancreatic fistula after pancreaticoduodenectomy. World J Surg 37(10): 2436-2442, 2013. PMID: 23838932. DOI: 10.1007/ s00268-013-2149-8

19 Fujiwara Y, Misawa T, Shiba H, Shirai Y, Iwase R, Haruki K, Furukawa K, Futagawa Y and Yanaga K: A novel postoperative inflammatory score predicts postoperative pancreatic fistula after pancreatic resection. Anticancer Res 33(11): 5005-5010, 2013 PMID: 24222143.

20 Liu Z, Jin K, Guo M, Long J, Liu L, Liu C, Xu J, Ni Q, Luo G and $\mathrm{Yu}$ X: Prognostic value of the crp/alb ratio, a novel inflammationbased score in pancreatic cancer. Ann Surg Oncol 24(2): 561-568, 2017. PMID: 27650825. DOI: 10.1245/s10434-016-5579-3

21 Kim MH, Ahn JY, Song JE, Choi H, Ann HW, Kim JK, Kim JH, Jeon YD, Kim SB, Jeong SJ, Ku NS, Han SH, Song YG, Choi JY, Kim YS and Kim JM: The c-reactive protein/albumin ratio as an independent predictor of mortality in patients with severe sepsis or septic shock treated with early goal-directed therapy. PLoS One 10(7): e0132109, 2015. PMID: 26158725. DOI: 10.1371/journal.pone.0132109

22 Yang WM, Zhang WH, Ying HQ, Xu YM, Zhang J, Min QH, Huang B, Lin J, Chen JJ and Wang XZ: Two new inflammatory markers associated with disease activity score- 28 in patients with rheumatoid arthritis: Albumin to fibrinogen ratio and c-reactive protein to albumin ratio. Int Immunopharmacol 62(293-298), 2018. PMID: 30048859. DOI: 10.1016/j.intimp.2018.07.007

23 Kakita A, Takahashi T, Yoshida M and Furuta K: A simpler and more reliable technique of pancreatojejunal anastomosis. Surg
Today 26(7): 532-535, 1996. PMID: 8840437. DOI: $10.1007 /$ bf00311562

24 Fujii T, Sugimoto H, Yamada S, Kanda M, Suenaga M, Takami $\mathrm{H}$, Hattori M, Inokawa Y, Nomoto S, Fujiwara M and Kodera Y: Modified blumgart anastomosis for pancreaticojejunostomy: Technical improvement in matched historical control study. J Gastrointest Surg 18(6): 1108-1115, 2014. PMID: 24733259. DOI: $10.1007 / \mathrm{s} 11605-014-2523-3$

25 Bassi C, Marchegiani G, Dervenis C, Sarr M, Abu Hilal M, Adham M, Allen P, Andersson R, Asbun HJ, Besselink MG, Conlon K, Del Chiaro M, Falconi M, Fernandez-Cruz L, Fernandez-Del Castillo C, Fingerhut A, Friess H, Gouma DJ, Hackert T, Izbicki J, Lillemoe KD, Neoptolemos JP, Olah A, Schulick R, Shrikhande SV, Takada T, Takaori K, Traverso W, Vollmer CR, Wolfgang CL, Yeo CJ, Salvia R and Buchler M: The 2016 update of the international study group (isgps) definition and grading of postoperative pancreatic fistula: 11 years after. Surgery 161(3): 584-591, 2017. PMID: 28040257. DOI: $10.1016 /$ j.surg.2016.11.014

26 Van Buren G, 2nd, Bloomston M, Hughes SJ, Winter J, Behrman SW, Zyromski NJ, Vollmer C, Velanovich V, Riall T, Muscarella P, Trevino J, Nakeeb A, Schmidt CM, Behrns K, Ellison EC, Barakat O, Perry KA, Drebin J, House M, Abdel-Misih S, Silberfein EJ, Goldin S, Brown K, Mohammed S, Hodges SE, McElhany A, Issazadeh M, Jo E, Mo Q and Fisher WE: A randomized prospective multicenter trial of pancreaticoduodenectomy with and without routine intraperitoneal drainage. Ann Surg 259(4): 605-612, 2014. PMID: 24374513. DOI: 10.1097/SLA.0000000000000460

27 Darnis B, Lebeau R, Chopin-Laly $X$ and Adham M: Postpancreatectomy hemorrhage (pph): Predictors and management from a prospective database. Langenbecks Arch Surg 398(3): 441-448, 2013. PMID: 23435636. DOI: 10.1007/ s00423-013-1047-8

28 Brown EG, Yang A, Canter RJ and Bold RJ: Outcomes of pancreaticoduodenectomy: Where should we focus our efforts on improving outcomes? JAMA Surg 149(7): 694-699, 2014. PMID: 24849180. DOI: 10.1001/jamasurg.2014.151

29 Watanabe Y, Nishihara K, Matsumoto S, Okayama T, Abe Y and Nakano T: Effect of postoperative major complications on prognosis after pancreatectomy for pancreatic cancer: A retrospective review. Surg Today 47(5): 555-567, 2017. PMID: 27704248. DOI: $10.1007 / \mathrm{s} 00595-016-1426-1$

30 Giglio MC, Spalding DR, Giakoustidis A, Zarzavadjian Le Bian A, Jiao LR, Habib NA and Pai M: Meta-analysis of drain amylase content on postoperative day 1 as a predictor of pancreatic fistula following pancreatic resection. Br J Surg 103(4): 328-336, 2016. PMID: 26791838. DOI: 10.1002/ bjs. 10090

31 Dagorn JC, Paradis D and Morisset J: Non-parallel response of amylase and chymotrypsinogen biosynthesis following pancreatic stimulation: A possible explanation for observed nonparallelism in pancreatic secretion. Digestion 15(2): 110-120, 1977. PMID: 838183. DOI: 10.1159/000197992

32 Colley CM, Fleck A, Goode AW, Muller BR and Myers MA: Early time course of the acute phase protein response in man. J Clin Pathol 36(2): 203-207, 1983. PMID: 6826776. DOI: 10.1136/jcp.36.2.203

33 Partelli S, Pecorelli N, Muffatti F, Belfiori G, Crippa S, Piazzai F, Castoldi R, Marmorale C, Balzano G and Falconi M: Early postoperative prediction of clinically relevant pancreatic fistula 
after pancreaticoduodenectomy: Usefulness of c-reactive protein. HPB (Oxford) 19(7): 580-586, 2017. PMID: 28392159. DOI: 10.1016/j.hpb.2017.03.001

34 Okada Y, Takahashi A, Ohmiya H, Kumasaka N, Kamatani Y, Hosono N, Tsunoda T, Matsuda K, Tanaka T, Kubo M, Nakamura Y, Yamamoto $\mathrm{K}$ and Kamatani N: Genome-wide association study for c-reactive protein levels identified pleiotropic associations in the IL6 locus. Hum Mol Genet 20(6): 1224-1231, 2011. PMID: 21196492. DOI: 10.1093/hmg/ddq551

$35 \mathrm{Xu} \mathrm{HJ}$, Ma Y, Deng F, Ju WB, Sun XY and Wang H: The prognostic value of c-reactive protein/albumin ratio in human malignancies: An updated meta-analysis. Onco Targets Ther 10: 3059-3070, 2017. PMID: 28790840. DOI: 10.2147/OTT.S137002

36 Kaplan M, Ates I, Akpinar MY, Yuksel M, Kuzu UB, Kacar S, Coskun $\mathrm{O}$ and Kayacetin E: Predictive value of c-reactive protein/albumin ratio in acute pancreatitis. Hepatobiliary Pancreat Dis Int 16(4): 424-430, 2017. PMID: 28823374. DOI: 10.1016/S1499-3872(17)60007-9

37 Winter JM, Cameron JL, Yeo CJ, Alao B, Lillemoe KD, Campbell KA and Schulick RD: Biochemical markers predict morbidity and mortality after pancreaticoduodenectomy. J Am Coll Surg 204(5): 1029-1036; discussion 1037-1028, 2007. PMID: 17481534. DOI: 10.1016/j.jamcollsurg.2007.01.026
38 Yin M, Si L, Qin W, Li C, Zhang J, Yang H, Han H, Zhang F, Ding S, Zhou M, Wu D, Chen $\mathrm{X}$ and Wang $\mathrm{H}$ : Predictive value of serum albumin level for the prognosis of severe sepsis without exogenous human albumin administration: A prospective cohort study. J Intensive Care Med 33(12): 687-694, 2018. PMID: 28013574. DOI: 10.1177/0885066616685300

39 Jenne $\mathrm{CN}$ and Kubes P: Platelets in inflammation and infection. Platelets 26(4): 286-292, 2015. PMID: 25806786. DOI: 10.3109/09537104.2015.1010441

40 Han JW, Oh JH, Rhim JW and Lee KY: Correlation between elevated platelet count and immunoglobulin levels in the early convalescent stage of kawasaki disease. Medicine (Baltimore) 96(29): e7583, 2017. PMID: 28723797. DOI: 10.1097/MD.0000 000000007583
Received October 13, 2019

Revised October 23, 2019

Accepted October 24, 2019 